\title{
Postpartum Haemorrhage Following Unsupervised Labour: The Role of the Anaesthetist
}

\author{
Longinus N. Ebirim**, Benjamin Lagiri, Omiepirisa Yvonne Buowari
}

Department of Anaesthesiology, University of Port Harcourt Teaching Hospital, Port Harcourt, Nigeria.

Email: "ginebirim@yahoo.com, yvonnebuowari@yahoo.com

Received July $12^{\text {th }}$, 2012; revised August 20 ${ }^{\text {th }}, 2012$; accepted September $24^{\text {th }}, 2012$

\begin{abstract}
Obstetric haemorrhage is a leading cause of maternal morbidity and mortality and sometimes the patients require anaesthesia in the course of treatment. A Para 3 Nigerian who delivered outside the hospital was rushed in to the hospital in a shocked state following a major obstetric haemorrhage. She was immediately resuscitated and general anaesthesia administered for hysterectomy. Anaesthesia was induced with ketamine, intubation facilitated with suxamethonium and muscle relaxation maintained with $5 \mathrm{mg}$ of atracurium while oxygen was administered. She received blood transfusion and the postoperative period was uneventful. There is need for emergency obstetric and anaesthetic services in developing and low income countries. There is need for continuous training in the administration of emergency anaesthesia to help reduce maternal morbidity and mortality. It is also necessary for blood bank services and antibiotics to be readily available.
\end{abstract}

Keywords: Haemorrhage; Anaesthesia; Morbidity; Mortality

\section{Introduction}

Every minute of every day, a woman dies in pregnancy or childbirth. The biggest killer is obstetric haemorrhage, the successful treatment of which is a challenge for both the developed and developing world [1]. Obstetric haemorrhage accounts for up to $70 \%$ of all causes of maternal mortality [2]. In Nigeria, only $31 \%$ of all deliveries take place in health facilities. About $67 \%$ of deliveries occur at home and are unattended by doctors or midwives, only $33.6 \%$ of all deliveries are attended by skilled attendants [2]. Public enlightenment and education on pregnancy, antenatal care, labour; postnatal care and prevention of mothers' death must be seriously commenced.

Obstetric haemorrhage remains one of the leading causes of preventable maternal morbidity and mortality worldwide. Life-threatening haemorrhage occurs in about 1 in every 1000 deliveries [3]. In the developing world, obstetric haemorrhage is the commonest cause of death in women less than 40 years with 150,000 deaths annually and remains the second leading cause of maternal death in the developed world [4]. Obstetric haemorrhage is often sudden, unexpected and may by associated with coagulopathy. Early recognition and treatment are essential to ensure the best outcome. Obstetric haemorrhage can be torrential quickly leading to shock and

${ }^{*}$ Corresponding author. death before transfer to another centre can be effected, so management must be established as quickly as possible [2]. The role of the anaesthetist in a case of postpartum haemorrhage following unsupervised delivery at home in Nigeria is being highlighted in this case report

\section{Case Presentation}

A thirty-two year old Para 3 was rushed into the unbooked labour ward of the University of Port Harcourt Teaching Hospital, Nigeria by a taxi driver and her 8 year old daughter in shock with a history of delivery in a taxi on her way to a health centre eight hours prior to presentation. On examination, she was conscious, in a shocked state, pale (paper white) in a pool of blood with cold calmly extremities. Blood pressure was unrecordable and pulse rate was very fast and tready. Packed cell volume was $10 \%$. Digital vaginal examination revealed profuse vaginal bleeding for which two Foley's urethral catheters were inserted into the uterus and the balloons inflated. Several clots of blood were removed from the uterus.

Intravenous access was established on both hands with 16G cannulae and she was resuscitated with $1(1 / 2)$ litres of $0.9 \%$ normal saline set up on one hand and 500 $\mathrm{ml}$ of dextrose water containing 20 international units of oxytocin which was set up on the other hand. Patient was transfused immediately with one unit of whole blood, 
which was donated by the unbooked labour ward obstetric registrar on duty since there was no relative to provide her medications. Urethral catheterization was done with Foleys urethral catheter to monitor urine output. She was also infused with $1 \mathrm{~L}$ of Hartmann's solution and blood pressure came up to $60 / 40 \mathrm{mmHg}$ and pulse rate was 160 beats per minute. Blood products were not available at the centre at the time the patient presented. Informed consent was obtained and four units of whole blood made available for surgery. She was wheeled into the theatre on the hospital bed, as she was too weak to transfer herself to the theatre trolley and there was urgency for the planned intervention measures. Five hundred millilitres of intravenous Hartman's solution was set up. Premedication was administered with $0.6 \mathrm{mg}$ atropine and $15 \mathrm{mg}$ pentazocine.

She was preoxygenated with oxygen at a flow rate of 5 litres per minute for five minutes by facemask. Induction of anaesthesia was with $50 \mathrm{mg}$ ketamine and intubation with $100 \mathrm{mg}$ suxamethonium and $7.5 \mathrm{~mm}$ internal diameter cuffed endotracheal tube. Muscle relaxation was maintained with $10 \mathrm{mg}$ intravenous atracurium while $100 \%$ oxygen was administered. Findings at surgery were a posterior uterine rupture and a curvellier uterus. Subtotal abdominal hysterectomy was done. Intraoperatively she received 3 units of blood and $500 \mathrm{ml}$ of Hartman's solution. She received two units of whole blood under frusemide cover postoperatively. Immediate postoperative pulse rate was $120 \mathrm{bpm}$ and blood pressure 100/50 mmhg. Anaesthesia was monitored intraoperatively with a pre-cordial stethoscope, a pulse oximeter, non-invasive sphygmomanometer, and Foleys' urethra catheter for urine output. Her postoperative packed cell volume was $21 \%$ and she was placed on analgesics, antibiotics, and haematinics postoperatively. Estimated blood loss was $500 \mathrm{ml}$.

She was discharged home on the eighth postoperative day and advised to complete her course of oral antibiotics, haematinics, and analgesic.

\section{Discussion}

Nigeria is a developing country burdened with poverty, ignorance, illiteracy, poor health care services, lack of social amenities especially in the rural areas, massive unemployment, and poor and unsure pension [2]. This patient resides in a Nigerian town with primary and secondary health care facilities, which render antenatal care services, but she did not make use of the services. She was on her way to the primary health centre at the time of delivery. She presented as an emergency yet her husband did not accompany her to the hospital. Her 8year-old daughter who was a minor and a taxi driver accompanied her to the hospital. Nigeria does not offer health insurance to all her citizens therefore in most $\mathrm{Ni}$ gerian hospitals; patients are required to pay for laboratory investigations and other bills even when it is an emergency. The Registrar on duty at the labour ward donated the first unit of blood. Obstetric emergencies are the leading causes of maternal mortality worldwide and particularly in developing countries where illiteracy, poverty, lack of antenatal care, poor transport facilities inadequate equipment and staffing combine to magnify the problem $[5,6]$. Haematological management includes regular monitoring of full blood count and coagulation screen with the appropriate use of blood products [4]. Major primary postpartum haemorrhage continues to top the list of causes of maternal mortality worldwide. The situation is worse in developing countries where more deaths are reported due to delay in seeking expert management [7]. An emergency can be defined as a situation of serious and often dangerous nature, developing suddenly and unexpectedly and demanding immediate attention in order to save life [8]. The uterine blood flow is as high as $750 \mathrm{ml} / \mathrm{min}$ [9], and this is probably the reason for the torrential nature of obstetric haemorrhage. The patient presented in shock. Anaesthesia was induced with ketamine because in major haemorrhage, intravenous ketamine $(1.5 \mathrm{mg} / \mathrm{kg})$ may better preserve cardiovascular stability [3]. Some induction agents such as thiopentone and propofol may result in significant hypotension in the presence of hypovolaemia. Atracurium, used in this case to maintain muscle relaxation has virtually no cardiovascular effects in clinical doses and is useful if renal function is uncertain [10]. Obstetric patients with severe haemorrhage may decompensate rapidly. Therefore, urgent surgery should not be delayed [3]. Regional anaesthesia is usually best avoided in the case of major obstetric haemorrhage as it prevents sympathetic compensation in a patient who is intravascularly deplete, leading to marked hypotension and inadequate perfusion of vital organs. General anaesthesia following a rapid sequence induction with cricoid pressure is therefore usually the technique of choice. Drug dosages for induction and maintenance of general anaesthesia may need to be modified according to the circulating volume status of the patient. Emergency peripartum hysterectomy is one of the life saving procedures performed after vaginal delivery or caesarean birth or in the immediate postpartum period in cases of intractable haemorrhage due to uterine atony, ruptured uterus and placental disorders [11]. It is usually reserved for the situations where conservative measures fail to control the haemorrhage as in this case. Fighting obstetric haemorrhage requires blood bank facilities, blood donation during the antenatal period, use of ergometrine, oxytocin, or the newest weapon in the armoury misopristol [2]. Unplanned births before arrival at the hospital remain a threat to maternal and 
neonatal health especially in low-income countries like Nigeria [12]. Exact numerical definitions of blood loss are unimportant as in this case. An estimated blood loss of $1000 \mathrm{ml}$ (or less with concurrent clinical signs of haemorrhagic shock as tachycardia, tachypneoea, prolonged capillary refill, oliguria and in extremis hypotension and altered cognitive function) should initiate the protocol for the management of major obstetric haemorrhage [3]. Several pairs of hands are needed to aid resuscitation, to fetch equipment, prepare the operating theatre, and transport blood samples to and from the laboratory. The choice of surgical procedure will depend on the expertise of the staff and availability of equipment. It requires deciding on the need for and in performing peripartum hysterectomy which is often challenging. Unnecessary delay must be avoided however and the difficult decision to perform hysterectomy should be made before mortality occurs.

\section{Conclusion}

Postpartum haemorrhage is a common obstetric emergency where prompt recognition and appropriate management can help to reduce associated maternal morbidity and potential mortality. The principles of management are to stop blood loss and replace circulating blood volume. The clinical state of the patient rather than the amount of blood loss should guide the clinician to the urgency of resuscitation. In a case of major obstetric haemorrhage resuscitation, monitoring, investigation and management should occur simultaneously. Postpartum haemorrhage can occur during any delivery. Prompt and competent management can avert maternal death. Successful management of postpartum haemorrhage relies on early diagnosis, resuscitation, and arrest of haemorrhage where there is an identifiable cause. The aim is to preserve life.

\section{REFERENCES}

[1] E. Ogboli-Nwasor, "Third Trimester Obstetric Haemorrhage: Still a Challenge,” League of Obstetric Anaesthe- tists of Nigeria Lectures and Maiden Lecture General Meeting, p. 7.

[2] A. C. Umezulike, "Maternal Mortality in Nigeria: The Present State and the Way Forward," Nigerian Journal of General Practice, Vol. 7, No. 9, 2006, pp. 5-18.

[3] S. Badwin and M. Rucklidge, "Management of Obstetric Haemorrhage," Update in Anaesthesia, Vol. 25, No. 2, 2009, pp. 42-46.

[4] B. Hunt, "Use of the Coagulation Laboratory and Near Patient Testing in Thrombosis and Bleeding in Obstetric Anaesthesia," In: R. Fernando and C. Elton, Eds., Three-Day Course on Obstetric Anaesthesia and Analgesia, 2008, pp. 53-54.

[5] J. Drife, “Maternal Mortality,” In: D. M. Lueslay and P. N. Baker Eds., Gynaecology and Evidence-Based Text for MRCOG, Arnold Publishers, London, 2004, pp. 196-204.

[6] W. O. Chukwudebelu, "Preventing Maternal Mortality in Developing Countries,” In: A. Okonofua and K. Odunsi, Eds., Contemporary Obstetrics and Gynaecology for Developing Countries, Women's Health and Action Research Centre, Benin, 2003, pp. 644-657.

[7] A. O. Arowojolu, "Managing Major Early (Primary) Postpartum Haemorrhage in Developing Countries," Tropical Journal of Obstetrics and Gynaecology, Vol. 20, No. 2, 2003, pp. 144-152.

[8] S. Campbell and C. Lee, “Obstetric Emergencies,” In: S. Campbell and C. Lee, Eds., Obstetrics by Ten Teachers, 17th Edition, Arnold Publishers, London, 2000, pp. 303317.

[9] C. Vicki, “Obstetric Haemorrhage,” In: R. Fernando and C. Elton, Eds., Three-Day Course on Obstetric Anaesthesia and Analgesia, 2008, pp. 46-52.

[10] D. A. B. Turner, “Emergency Anaesthesia,” In: A. R. Aitkenhead, G. Smith and D. J. Rowbotham, Eds., Textbook of Anaesthesia, 5th Edition, Churchill Livingstone Elsevier Publishers, London, 2007, pp. 540-553.

[11] N. Nusrat and A. S. Nisar, "Emergency Peripartum Hysterectomy: Frequency, Indications, and Maternal Outcome," Journal of Ayub Medical College Abbottabad, Vol. 21, No. 1, 2009, pp. 48-51.

[12] S. E. Adaji, S. B. Bature and O. S. Shittu, "Unplanned Births before Arrival at the Hospital in a Low Resource Setting: A Case Setting," Nigerian Medical Journal, Vol. 18, No. 4, 2009, pp. 431-433. 